\title{
UNIDADES DE CONSERVAÇÃO E CICLOTURISMO: CONTEXTOS E POSSIBILIDADES
}

\author{
EMERSON BARÃO RODRIGUES SOLDADO ${ }^{1}$ \\ ODALÉIA TELLES MARCONDES MACHADO QUEIROZ ${ }^{2}$ \\ TERESA CRISTINA MAGRO LINDENKAMP ${ }^{3}$
}

DOI: https://doi.org/10.47977/2318-2148.2021.v9n14p59

\begin{abstract}
RESUMO
Apesar dos resultados de pesquisas que apontam a necessidade de aumentar a proteção dos ecossistemas brasileiros, existem questionamentos sobre a designação de terras públicas em áreas de proteção ambiental. Para atingir os objetivos relacionados à conservação ambiental, uma das ferramentas mais comuns neste âmbito são as unidades de conservação (UC). Estas passam por um constante processo de ressignificação e afirmação de seu papel na conservação e no cumprimento dos Objetivos do Desenvolvimento Sustentável (ODS) da Organização das Nações Unidas (ONU). Muitos estudos apontam a importância de se compreender e estimular o uso sustentável dessas áreas. Dentre as formas de uso, vem se destacando o ciclismo, sobretudo em parques. Pesquisas recentes mostram que esta atividade gera pouco impacto ambiental negativo. Apesar disso, a maioria dos parques nacionais e estaduais brasileiros têm restrições ou não permitem o uso de bicicleta, o que inviabiliza a atividade de cicloturismo, que tem grande crescimento nos últimos anos. $\mathrm{O}$ presente artigo insere-se neste contexto ao realizar um levantamento bibliográfico sobre o tema do uso de bicicletas em UC e o cicloturismo. A partir dos dados obtidos, fica claro o potencial de uso dos parques nacionais e estaduais brasileiros para o cicloturismo, que é apontada como uma importante atividade de lazer, bem-estar e de baixo impacto, com potencial de desenvolvimento socioeconômico. O perfil do cicloturista é bem variável e seus objetivos de viagem tornam possível o aproveitamento de todo território brasileiro. Apesar disso, poucas alternativas de cicloturismo em parques nacionais e estaduais são possíveis e, consequentemente, pouco se discute sobre isso nos trabalhos científicos. Fica clara, portanto, a necessidade de aprofundamentos em pesquisas e propostas nestas temáticas e a articulação com as entidades gestoras e as comunidades.
\end{abstract}

Palavras-chaves: Ciclismo; Turismo; Parques Estaduais; Parques Nacionais

\footnotetext{
${ }^{1}$ Professor do Instituto Federal da São Paulo - Campus Suzano. Doutorando em Ecologia Aplicada pela Esalq/USP. Mestre em História da Ciência. Licenciado e Bacharel em Ciências Biológicas. Email: barao@usp.br

2 Professora da Universidade de São Paulo, Escola Superior de Agricultura Luiz de Queiroz, Departamento de Economia. Doutorado em Ciências da Engenharia Ambiental. Mestrado em Geociências e meio ambiente. Turismóloga, Geógrafa e Pedagoga. E-mail: otmmquei@usp.br

3 Professora da Universidade de São Paulo, Escola Superior de Agricultura Luiz de Queiroz, Departamento de Ciências Florestais. Doutorado em Ciências da Engenharia Ambiental. Mestrado em Ciência Florestal. Graduação em Engenharia Florestal. E-mail: teresa.magro@usp.br
} 


\title{
PROTECTED AREAS AND BICYCLE TOURISM: CONTEXTS AND POSSIBILITIES
}

\begin{abstract}
Despite the results of research that indicate the need to increase the protection of Brazilian ecosystems, there are questions about the designation of public lands in areas of environmental protection. To achieve the objectives related to environmental conservation, one of the most common tools in this area are conservation units (UC). These undergo a constant process of reframing and affirming their role in the conservation and fulfillment of the Sustainable Development Goals (SDGs) of the United Nations (UN). Many studies point to the importance of understanding and encouraging the sustainable use of these areas. Among the forms of use, cycling has been highlighted, especially in parks. Recent research shows that this activity generates little negative environmental impact. Despite this, most Brazilian national and state parks have restrictions or do not allow the use of bicycles, which makes cycling tourism unfeasible, which has grown significantly in recent years. This article is part of this context by conducting a bibliographic survey on the topic of bicycle use in UC and cycle tourism. From the data obtained, it is clear the potential use of Brazilian national and state parks for cycle tourism, which is identified as an important leisure, well-being and low-impact activity, with potential for socioeconomic development. The profile of the cyclotourist is quite variable and their travel objectives make it possible to take advantage of the entire Brazilian territory. Despite this, few alternatives for cycle tourism in national and state parks are possible and, consequently, little is discussed about this in scientific works. It is clear, therefore, the need for further research and proposals on these themes and the articulation with management entities and communities.
\end{abstract}

Keywords: Cycling; Tourism; State Parks; National Parks

\section{UNIDADES DE CONSERVAÇÃO E O USO PÚBLICO}

Para que os Objetivos do Desenvolvimento Sustentável (ODS) da Organização das Nações Unidas (ONU) sejam alcançados, diversas estratégias sociais, econômicas e políticas devem ser articuladas. Neste sentido, uma importante ferramenta para o desenvolvimento de objetivos, como o da "Saúde e bem-estar", são as unidades de conservação (UC), definidas pela legislação federal, Lei n 9.985 , de 2000, como:

\begin{abstract}
Espaço territorial e seus recursos ambientais, incluindo as águas jurisdicionais, com características naturais relevantes, legalmente instituído pelo Poder Público, com objetivos de conservação e limites definidos, sob regime especial de administração, ao qual se aplicam garantias adequadas de proteção (BRASIL, 2000).
\end{abstract}

Estas podem ser classificadas em duas categorias: Unidades de Proteção Integral e Unidades de Uso Sustentável. No primeiro grupo, estão inseridos Estação Ecológica, 
Reserva Biológica, Parque Nacional ${ }^{4}$, Monumento Natural, e Refúgio de Vida Silvestre (BRASIL, 2000). Para cada uma destas categorias, a legislação traz definições e especifica suas possibilidades de uso.

Entretanto, no que concerne o objetivo deste artigo, destaca-se a categoria Parque Nacional:

O Parque Nacional tem como objetivo básico a preservação de ecossistemas naturais de grande relevância ecológica e beleza cênica, possibilitando a realização de pesquisas científicas e o desenvolvimento de atividades de educação e interpretação ambiental, de recreação em contato com a natureza e de turismo ecológico (BRASIL, 2000).

Diante desta definição, os Parques Nacionais apresentam uma possibilidade de conciliar a conservação ambiental com atividades de cunho recreativo e turístico, desde que sejam planejados e executados por profissionais qualificados e de forma multidisciplinar. Isto pode representar uma forma sustentável de conservação, criar um sentimento de pertencimento e apropriação por parte da população, auxiliando na conservação destas áreas (REIS e QUEIROZ, 2016).

O uso público envolve a recreação, a pesquisa, atividades educacionais e manifestações religiosas (MAGRO; 1999). Dos Santos (2020) apresenta uma análise destacando a importância da percepção ambiental dos usuários para o entendimento destas possibilidades de uso.

O estudo de Vallejo (2013) divide o uso público de UC em possíveis benefícios: o Econômico, relacionado ao financiamento de outras áreas menos atrativas, aporte financeiro para a própria área protegida, e maior arrecadação de impostos; o Coletivo, relacionado à geração de emprego e renda, redução de conflitos, valorização do patrimônio cultural local, e participação conjunta nas decisões; os Pessoais, envolvendo atividades físicas, redução do estresse, contato com a natureza, relaxamento físico e mental, e práticas solidárias; e a Conservação Ambiental, que abarca melhorias na infraestrutura, práticas educativas, difusão da informação ambiental, conscientização pública, e preservação de espécies.

Neste sentido, o uso público dos parques é uma importante ferramenta, além de se constituir como um direito do cidadão, embora tenhamos ainda uma ideia de que eles devem ser restritos ao uso, funcionando como verdadeiras fortalezas da vida selvagem (REIS e QUEIROZ, 2016). Ainda nas palavras das autoras:

Este fato é questionado por grupos, especialmente os organizados como montanhistas, ciclistas e observadores de aves. As unidades de conservação deveriam cada dia mais ter este público como parceiro na elaboração das regras, pois estes podem contribuir na valorização e proteção das UCs. De forma geral, são pessoas conscientizadas que

\footnotetext{
4 Na legislação, estes parques, quando criados pelo Estado ou Município, serão denominados, respectivamente, Parque Estadual e Parque Natural Municipal (BRASIL, 2000).
} 
gostam de estar em contato com a natureza e prezam pelos lugares conservados (REIS e QUEIROZ, 2016, p. 132).

Destaca-se que o uso público dos parques poderia mudar olhares sobre as questões relativas à conservação da natureza, mas também pode aumentar o risco de degradação ambiental, caso não seja bem planejado (PIMENTEL et al, 2016). Desta forma, vê-se o uso público dos parques como um pilar de enorme importância, tanto para a conservação, como para auxiliar na compreensão da sociedade de sua importância, nos mais diversos aspectos (PIMENTEL, MAGRO, SILVA-FILHO, 2011). Estes autores complementam ainda que a visão de um parque totalmente intocável gera uma paisagem virtual, desconectada da realidade e fruto de muitos dos problemas vivenciados no manejo destas UC.

Destaca-se também que toda UC deve possuir um plano de manejo, corretamente elaborado e aprovado, e periodicamente revisado. Nele, as atividades permitidas devem ser previstas, incluindo o levantamento de seus impactos (BRASIL, 2002). Diversos autores (REIS e QUEIROZ, 2016; PIMENTEL et al, 2016; PIMENTEL, MAGRO, SILVAFILHO, 2011) salientam a importância dada a esse documento, que pode ser uma excelente ferramenta para evitar a citada generalização, analisando quais atividades são possíveis. Vallejo (2013) assinala que, para a construção destes documentos, são importantes os estudos sobre o perfil dos visitantes, suas demandas e percepções.

Evidentemente, as atividades relacionadas ao uso recreativo de parques estão associadas aos impactos ambientais, principalmente decorrentes da compactação do solo em trilhas (MAGRO, 1999; PINTO et al, 2008; MARION e COLE, 1996; VALLEJO, 2013). Sobre isso, Vallejo (2013) destaca que o grau de impacto negativo tem uma relação direta com a frequência e volume de uso, além da natureza da atividade. O autor explana que os impactos negativos são das mais diversas ordens, desde alterações na flora e fauna, até o despejo de esgoto, lixo e problemas nas comunidades do entorno. Sobre isso, o autor complementa:

$$
\begin{aligned}
& \text { Da mesma forma que o uso público traz benefícios (pessoais, } \\
& \text { econômicos, sociais e ambientais), existem os riscos e impactos } \\
& \text { negativos associados. Estes impactos podem repercutir sobre a } \\
& \text { qualidade da conservação ambiental e sobre o próprio uso, quando os } \\
& \text { efeitos da degradação acabam desestimulando a visitação (VALLEJO, } \\
& 2013 \text { p. 25). }
\end{aligned}
$$

Dentre os impactos positivos e negativos, muitas opções de uso vêm se destacando, sobretudo na prática esportiva e atividades ao ar livre, como por exemplo arborismo, escalada, canoagem, trekking, hikking, cavalgadas, corridas de aventura e ciclismo. E neste campo, temos menos pesquisas sobre os impactos negativos específicos destas atividades, o que sugere uma importante área de estudos (REIS e QUEIROZ, 2016).

Autoras como Reis e Queiroz (2016) elencam diversas destas atividades ao ar livre, classificando as que poderiam ou não ser aplicadas no Parque Estadual da Cantareira em 
São Paulo, destacando as que já ocorrem. Nota-se que, em sua maioria, as atividades que poderiam ser desenvolvidas não são permitidas atualmente. Salienta-se que as autoras chamam a atenção para o fato de que seus levantamentos são iniciais, e que "qualquer atividade a ser implantada deve ser primeiramente avaliada por profissionais capacitados e estar prevista no seu plano de manejo" (REIS e QUEIROZ, 2016, p. 135).

Deve-se lembrar que estas atividades podem trazer impactos positivos, além dos negativos, como destacam as pesquisadoras Bartoletti e Magro (2016), ao explanarem sobre as corridas de aventura:

(...) trazem ainda o impacto positivo de, efetivamente, colocar as pessoas em contato físico com os ambientes naturais, ao invés de propiciar um contato mediado por veículos que implica que a natureza é apenas uma paisagem (BARTOLETTI e MAGRO, 2016 p.5).

Corroborando com estas ideias, estudos como os de Tahara, Carnicelli Filho e Schwartz (2006), e os de Olafsdottir (2020), evidenciaram que atividades ao ar livre, em contato com a natureza, trouxeram maiores benefícios de bem-estar físico e metal para as pessoas.

As autoras Bartoletti e Magro (2016) destacam ainda que, nos últimos anos, tem-se levantado questões cada vez mais interdisciplinares sobre a melhor gestão das UC e sua relação com as atividades nelas desenvolvidas, permitindo o uso recreativo prolongado e sustentável. Assim, fica clara a importância de estudos socioambientais mais aprofundados sobre o assunto.

Diante deste contexto, o presente artigo teve como objetivo realizar um levantamento bibliográfico sobre a prática de ciclismo em unidades de conservação, bem como aspectos relacionados ao cicloturismo no Brasil e a intersecção das duas temáticas. Para tanto, foram realizadas pesquisas em bases de dados como a Web of Science e o Google Acadêmico.

As palavras-chaves pesquisadas e combinadas foram: cicloturismo, turismo de bicicleta, cicloviagem, unidades de conservação, mountain bike, cycle tourism e protected areas. Foram analisados os artigos publicados entre os anos de 2000 e 2021 que se relacionavam com o cicloturismo no contexto brasileiro. Em relação ao uso de bicicletas em áreas protegidas, não houve restrição em relação ao país na qual a pesquisa se inseria. Além disso, também foram realizadas pesquisas com as mesmas palavras-chaves no site do Ministério do Turismo e no site do Instituto Chico Mendes de Conservação da Biodiversidade.

\section{CICLOTURISMO NO BRASIL: UM BREVE LEVANTAMENTO}

A própria definição de cicloturismo é complexa, sobretudo no contexto brasileiro. Existem autores, como Roldan (2000), definem que cicloturismo é aquele em que o deslocamento da viagem se dá pelo uso da bicicleta e dura vários dias. Autores como Junior et al (2011) apresentam a definição de que cicloturismo é qualquer viagem ou passeio 
turístico no qual se utiliza a bicicleta como meio de transporte, e o que diferencia o cicloturismo de um passeio de bicicleta é exatamente o conceito de turismo, que leva em consideração fatores como estar fora de sua residência habitual.

Entretanto, ao se realizar um levantamento bibliográfico em bases de dados como Google Acadêmico, muitas vezes o termo cicloturismo é utilizado em trabalhos cujo o escopo parece tratar de um passeio de bicicleta. Mas existe outra interpretação: muitas vezes, o turista se desloca de sua residência por outro meio de transporte para chegar no destino, mas o faz para usufruir das possibilidades ciclísticas da região, sendo assim um tipo de cicloturismo. Ou seja, esse tipo de turismo não é apenas aquele no qual o deslocamento é feito inteiramente pela bicicleta, mas aquele em que o deslocamento se deu por intermédio dela (VIACICLO ${ }^{5}$, sem data). Outra forma de entendimento do termo cicloturismo é a utilização da bicicleta por parte do turista regular para deslocamentos com fins culturais, de lazer e/ou aventura (BECKER, BECKER e PISONI DA SILVA, 2020; FALBO, EDRA e TEIXEIRA, 2019; IHA, 2017).

Buscando uma definição sobre esta temática, as autoras Teixeira e Edra (2020) propuseram que a melhor expressão a ser utilizada seria "Turismo de Bicicleta". Este seria um segmento turístico subdividido em duas modalidades: cicloturismo urbano, para deslocamentos turísticos curtos, e cicloviagem, na qual a bicicleta é o principal meio de deslocamento durante toda a viagem.

Assim, o termo cicloturismo é complexo, sendo necessário maiores aprofundamentos teóricos sobre o assunto. Mas, para fins metodológicos, utilizou-se todas estas definições para a busca em periódicos e textos jornalísticos. Entretanto, destaca-se a definição de cicloturismo de Sartori (2020):

o cicloturismo pode ser definido como viagens a regiões próximas ou diferentes da moradia fixa do sujeito, guiadas ou não, individualmente ou em grupos, com a participação ativa e as experiências culturais e ambientais como principais motivações ao longo da rota ou percurso escolhido (...) Não restringir o conceito sobre viagens distantes da moradia e mais de um dia é importante pois muitos ciclistas utilizam da própria bicicleta para chegar até o destino, em viagens de ida e volta no mesmo dia, não necessitando do deslocamento com veículos em parte do trajeto (SARTORI, 2020, p.18).

Em relação às atividades turísticas, o cicloturismo apresenta-se como uma alternativa sustentável e que movimenta o turismo rural, o ecoturismo, turismo de aventura, turismo cultural e gastronômico, trazendo diversos benefícios, tanto para os turistas, como para as comunidades envolvidas (CARDOSO, KARAM, e SANTOS, 2016). Destaca-se que o cicloturismo se diferencia do turismo esportivo. Isso, porque o segundo tem como foco o esporte, e o turismo permanece em segundo plano (CARVALHO, RAMOS e SYDOW,

5 ViaCiclo é a Associação dos Ciclousuários da Grande Florianópolis. Trata-se de uma organização não governamental fundada em 2001, com objetivo de promover o uso da bicicleta no transporte, esporte e lazer. 
2013). Documentos como "Circuitos de cicloturismo: manual de incentivo e orientação para os municípios brasileiros" (VIACICLO, sem data) destacam que o turista comum geralmente procura um destino, enquanto o cicloturista se interessa pelo trajeto, ou seja, todo lugar é seu destino. O cicloturista viaja para ficar em contato com a natureza, conhecer zonas rurais e se relacionar com a comunidade local. Ele vive intensamente o trajeto e valoriza tanto o percurso quanto o destino (JENOVEVA-NETO e PINTO VIEIRA, 2019). Ferreira, de Mello e Liberali (2010) complementam que o cicloturismo atua nos indivíduos como um grande promotor da saúde e bem-estar, reduzindo a gordura corporal e aumentando a massa corporal magra.

Em relação ao perfil dos praticantes de cicloturismo, segundo Viaciclo (sem data), o cicloturista médio tem em torno de 30 anos de idade, pedala em pequenos grupos durante até uma semana, transporta sua bicicleta no ônibus até o início do roteiro, hospeda-se em pousadas e gasta mais de 50 reais por dia. Saldanha et al (2019), em uma pesquisa realizada em 2018 sobre o cicloturismo no Brasil, levantou dados e informações sobre o segmento do cicloturismo identificando diferentes perfis de viajantes, suas demandas e desejos de consumo. Para isso, foram realizados questionários on-line com 1.196 respostas válidas, no qual 591 respondentes declararam ter realizado ao menos uma viagem utilizando a bicicleta como principal modo de transporte. As maiores motivações do usuário foram: aventura, maior contato com a natureza, maior contato com a população local e custo (menor custo financeiro de viagem). Os fatores impeditivos foram: segurança no trânsito, falta ou má conservação de infraestrutura cicloviária e segurança pública. A grande maioria dos cicloturistas mantém uma média de 1 a 2 viagens anuais de bicicleta. As faixas de gastos totais em uma viagem por bicicleta podem ser englobadas entre $\mathrm{R} \$ 100,00$ e $\mathrm{R} \$ 2.999,99$. $\mathrm{O}$ estudo destaca que, apesar de uma maior preponderância de determinadas classes de renda, idade, ou escolaridade, o cicloturismo é acessível para todos os perfis. Saldanha et al (2019) destaca uma grande demanda por maiores estruturas cicloviárias e que os cicloturistas optam por rotas delimitadas e regiões com apoio aos ciclistas.

Sartori (2021), em seu levantamento sobre o perfil de cicloturistas em Santa Catarina, Brasil, destaca que as principais motivações dos entrevistados para a prática do cicloturismo foram: exercício físico (29\%), conhecer paisagens naturais (24\%), realizar novas amizades (17\%) e conhecer o patrimônio histórico natural (11\%).

Por meio do já mencionado levantamento bibliográfico de artigos publicado sobre o cicloturismo no Brasil, encontram-se algumas propostas de rotas. Carvalho, Ramos e Sydow (2013) apresentam duas rotas cicloturísticas no Estado do Tocantins: AraguaínaCachoeira do Jenipapo, com aproximadamente $50 \mathrm{~km}$ de extensão, e Nova OlindaPalmeirante, de $80 \mathrm{~km}$ de extensão. A pesquisa pontuou as dificuldades de cada roteiro, sobretudo a pouca infraestrutura de receptivo e problemas nas rodovias. Entretanto, Carvalho, Ramos e Sydow (2013) destacam que o cicloturismo pode trazer investimentos 
para as regiões. Este trabalho trata de uma proposta teórica, ainda em fase de implementação prática.

Outra proposta foi apresentada por Almeida, Ramos e Gabriel-Neto (2017). Trata-se de uma rota cicloturística no Polo do Agreste, um importante indutor turístico do interior de Pernambuco. Ela estaria dividida da seguinte forma: Trecho 1) Gravatá - Serra Negra, 31,00 km; Trecho 2) Serra Negra - Caruaru, 31,80 km; Trecho 3) Caruaru - Bonito, 52,10 km; Trecho 4) Bonito - Gravatá, 67,70 km. Foi proposta a implantação de 323 placas de sinalização que foram projetadas para guiar o cicloturista em cada entrada e bifurcação, indicando a quilometragem e altimetria. Pode-se iniciar o trajeto em qualquer um dos trechos. O circuito trará ao Município de Gravatá um importante impacto na economia e no desenvolvimento, visto que a cidade já é conhecida pelos ciclistas pernambucanos como o paraíso das trilhas de bicicleta.

Alguns trabalhos apresentam potenciais de uso para o cicloturismo pouco explorados, como o citado por Iha (2017), que destaca a cidade de São Paulo, Brasil, como um polo do turismo de negócios, em que os turistas também podem usufruir das estruturas de lazer e gastronômicas da cidade. São destacadas a malha cicloviária da cidade, as ruas abertas de lazer aos domingos e as ciclofaixas de lazer. Neste ponto, o mesmo autor destaca a Avenida Paulista, um dos principais pontos turísticos da cidade de São Paulo, por sua grande quantidade de atrativos turísticos, bem explorados pela mídia, infraestrutura cicloviária e, além disso, por ser uma das ruas em que aos domingos o trânsito de veículos motorizados é interrompido.

Outros trabalhos apresentam propostas já concretizadas, com resultados significativos, como o de Becker, Becker e Pisoni da Silva (2020), que organiza um passeio ciclístico passando pelos atrativos turísticos urbanos de um município do Rio Grande do Sul, Jaguarão. Foi criado um roteiro para percorrer os principais patrimônios históricos desta cidade. O roteiro foi pensado para ser acessível para diferentes faixas etárias de ciclistas, possuindo sete quilômetros percorridos em duas horas. Participaram cinquenta ciclistas, dos quais $89 \%$ aprovaram o evento e sugeriram incluir outros pontos turísticos e novas rotas. A pesquisa chegou à conclusão de que o evento colaborou para a divulgação do turismo histórico-cultural na cidade, despertando também, aos autóctones, o reconhecimento de sua importância para a formação do município.

Outros exemplos podem ser encontrados em trabalhos como no de Cardoso, Karam, e Santos (2016), que apresentam um projeto desenvolvido na região da Serra dos Tapes, no Rio Grande do Sul, nos municípios de Pelotas, Canguçu, Morro Redondo, Turuçu e São Lourenço do Sul. Foram criados 17 eventos cicloturísticos por meio da condução de grupos de ciclistas urbanos até espaços rurais, nos quais são realizados roteiros que incluem incursões de bicicleta em uma ou mais propriedade familiar em transição agroecológica. Outro exemplo do sul do Brasil é o projeto de Belotto, Nakamori e Prado (2019), em Curitiba-PR. A partir de 2013, o projeto passou a organizar um calendário anual com vários 
passeios de bicicleta. Desde então, o projeto organiza em média sete passeios por ano, incluindo a descida para o litoral, via Estrada da Graciosa. O projeto atingiu inúmeras pessoas, tendo o recorde de inscritos no ano de 2018, com 150 pessoas, limite máximo do evento.

Outras pesquisas analisam eventos cicloturísticos já existentes, como Baptista e Cochinski (2015) e Baptista e de Goveia (2019), que constataram os inúmeros benefícios que o evento Cicloturismo (Irati-Paraná) proporciona à população da região, como educação ambiental, a movimentação da economia local e divulgação dos potenciais turísticos existentes nos arredores.

Diversas questões são levantadas sobre a infraestrutura e o apoio ao cicloturista. Segovia (2019) apresenta que é evidente a falta de articulação entre os setores da governança para melhorarem os investimentos a fim de que a bicicleta seja vista como um importante elemento para a mobilidade e turismo. Em concordância com estas ideias, Falbo, Edra e Teixeira (2019) asseveram que a rede hoteleira de Niterói-Rio de Janeiro não vislumbra o segmento cicloturístico como um potencial mercado. Nesse sentido, Iha (2017) conclui que o cicloturismo no Brasil ainda é muito incipiente, mas com perspectivas de aumento para os próximos anos. Nazareth (2017) vai além e discute a importância da acessibilidade no cicloturismo, destacando que uma viagem de bicicleta não precisa ser, necessariamente, um desafio e aventura, mas pode ocorrer também em um local estruturado e acessível.

Em relação às unidades de conservação, não há trabalhos sistematizados que enfatizam o cicloturismo. Destaca-se o texto jornalístico de Fialho (2017), do Ministério do Turismo, em que o autor salienta a crescente procura por viagens de bicicleta no país e que novos roteiros estão surgindo. Fialho (2017) apresenta a Volta das Transições, no interior de Minas Gerais, que conta com diversos atrativos naturais, como o Parque Estadual de Ibitipoca, e atrativos históricos, como a Fazenda Santa Clara.

O Quadro 1, a seguir, sintetiza o tema central dos artigos apresentados sobre a temática do cicloturismo, destacando se os seus escopos envolvem, de alguma forma, Unidades de Conservação. Estes artigos foram levantados na base de dados Google Acadêmico, com as seguintes palavras-chaves: Cicloturismo, turismo de bicicleta, cicloviagem e cycle tourism. Foram analisados artigos que tratavam do cicloturismo no contexto brasileiro, publicados entre os anos de 2000 e 2021. Também foram buscadas as mesmas palavras-chaves nos sites do Ministério do Turismo e no Instituto Chico Mendes de Conservação da Biodiversidade. 
Quadro 1 - Sistematização dos artigos discutidos, com suas temáticas centrais, e se envolvem UC.

\begin{tabular}{|c|c|c|}
\hline Referência & Temática principal & Envolve UC \\
\hline $\begin{array}{l}\text { Almeida, Ramos e } \\
\text { Gabriel Neto, } 2017 .\end{array}$ & $\begin{array}{l}\text { Descrição de uma rota de } \\
\text { cicloturismo. }\end{array}$ & Não. \\
\hline $\begin{array}{l}\text { Baptista e Cochinski, } \\
2015 .\end{array}$ & $\begin{array}{l}\text { Análise perfil de participantes de } \\
\text { um evento de cicloturismo. }\end{array}$ & Não. \\
\hline $\begin{array}{r}\text { Baptista e de } \\
\text { Goveia, } 2019 .\end{array}$ & $\begin{array}{c}\text { Levantamento das } \\
\text { potencialidades de um evento de } \\
\text { cicloturismo. }\end{array}$ & Não. \\
\hline $\begin{array}{l}\text { Becker, Becker e } \\
\text { Pisoni da Silva, } \\
2020 .\end{array}$ & $\begin{array}{l}\text { Descrição de um evento de } \\
\text { cicloturismo urbano. }\end{array}$ & Não. \\
\hline $\begin{array}{l}\text { Belotto, Nakamori, e } \\
\text { Prado, } 2019 .\end{array}$ & $\begin{array}{c}\text { Resultados de um programa de } \\
\text { extensão sobre ciclismo, } \\
\text { destaque para eventos de } \\
\text { cicloturismo urbano e ao litoral. }\end{array}$ & $\begin{array}{c}\text { Parcialmente. } \\
\text { Apesar de não fazer } \\
\text { menção direta, os eventos } \\
\text { perpassam áreas } \\
\text { protegidas. }\end{array}$ \\
\hline $\begin{array}{l}\text { Cardoso, Karam e } \\
\text { Santos, } 2016 .\end{array}$ & $\begin{array}{l}\text { Análise de um projeto de } \\
\text { eventos de cicloturismo rural. }\end{array}$ & Não. \\
\hline $\begin{array}{l}\text { Carvalho, Ramos e } \\
\text { Sydow, } 2013 .\end{array}$ & $\begin{array}{l}\text { Levantamento da possibilidade } \\
\text { de implementação de roteiros de } \\
\text { cicloturismo. }\end{array}$ & $\begin{array}{c}\text { Parcialmente. } \\
\text { Apesar de citar diversas } \\
\text { vezes a conservação } \\
\text { ambiental, não explora } \\
\text { as áreas protegidas. }\end{array}$ \\
\hline $\begin{array}{l}\text { Falbo, Edra, e } \\
\text { Teixeira, } 2019 .\end{array}$ & $\begin{array}{l}\text { Análise da infraestrutura local } \\
\text { para recepção de cicloturistas. }\end{array}$ & Não. \\
\hline $\begin{array}{l}\text { Ferreira, de Mello, e } \\
\text { Liberali, } 2010 .\end{array}$ & $\begin{array}{l}\text { Análises fisiológicas do efeito } \\
\text { de uma viagem de bicicleta. }\end{array}$ & Não. \\
\hline Fialho, 2017. & $\begin{array}{l}\text { Texto jornalístico sobre roteiros } \\
\text { de cicloturismo. }\end{array}$ & $\begin{array}{c}\text { Sim. } \\
\text { Cita o Parque Estadual } \\
\text { do Ibitipoca. } \\
\end{array}$ \\
\hline Iha, 2017. & $\begin{array}{c}\text { Análise dos potenciais do } \\
\text { cicloturismo na cidade de São } \\
\text { Paulo. }\end{array}$ & Não. \\
\hline $\begin{array}{c}\text { Jenoveva-Neto e } \\
\text { Pinto-Vieira, } 2019 .\end{array}$ & $\begin{array}{l}\text { Artigo cita as potencialidades e } \\
\text { vantagens de rotas de } \\
\text { cicloturismo para uma região de } \\
\text { Santa Catarina. }\end{array}$ & Não. \\
\hline
\end{tabular}




\begin{tabular}{|c|c|c|}
\hline Junior et al, 2011. & $\begin{array}{l}\text { Descrição de um projeto de } \\
\text { educação ambiental com a } \\
\text { temática do cicloturismo. }\end{array}$ & $\begin{array}{c}\text { Não. } \\
\text { Entretanto cite sobre UC } \\
\text { no texto. }\end{array}$ \\
\hline Melo, 2017. & $\begin{array}{c}\text { Texto jornalístico que explora } \\
\text { oito unidades de conservação } \\
\text { que são permitidas o uso de } \\
\text { bicicletas. }\end{array}$ & $\begin{array}{c}\text { Sim. } \\
\text { Texto apresenta diversas } \\
\text { UC que permitem } \\
\text { prática de ciclismo. }\end{array}$ \\
\hline Nazareth, 2017. & $\begin{array}{l}\text { Texto sobre as possibilidades de } \\
\text { cicloturimo para pessoas que } \\
\text { não possuem hábito de viajar de } \\
\text { bicicletas, com limitações físicas } \\
\text { ou de saúde. }\end{array}$ & Não. \\
\hline $\begin{array}{l}\text { Reis e Queiroz, } \\
2016 .\end{array}$ & $\begin{array}{l}\text { Cita possibilidades de uso do } \\
\text { Parque Estadual da Cantareira, } \\
\text { dentre elas o ciclismo. }\end{array}$ & $\begin{array}{c}\text { Sim. } \\
\text { Cita as potencialidades } \\
\text { do ciclismo em um } \\
\text { Parque Estadual. }\end{array}$ \\
\hline Roldan, 2000. & $\begin{array}{l}\text { Texto apresenta diversas } \\
\text { definições par ao ciclismo, } \\
\text { cuidados fisiológicos e } \\
\text { equipamentos para uma } \\
\text { cicloviagem. }\end{array}$ & Não \\
\hline Saldanha et al, 2019. & $\begin{array}{l}\text { Artigo apresentando o perfil dos } \\
\text { cicloturistas brasileiros. }\end{array}$ & $\begin{array}{c}\text { Não. } \\
\text { Embora apresente que a } \\
\text { aventura e o contato com a } \\
\text { natureza são os maiores } \\
\text { motivadores das viagens } \\
\text { de bicicletas. }\end{array}$ \\
\hline Sartori, 2020. & $\begin{array}{c}\text { Artigo com uma análise } \\
\text { qualitativa de um evento de } \\
\text { cicloturismo em Santa Catarina. }\end{array}$ & Não. \\
\hline Sartori, 2021. & $\begin{array}{c}\text { Artigo realiza uma análise } \\
\text { quantitativa do perfil dos } \\
\text { cicloturistas de Santa Catarina. }\end{array}$ & $\begin{array}{c}\text { Não. } \\
\text { Cita que conhecer as } \\
\text { paisagens naturais é uma } \\
\text { das maiores motivações } \\
\text { para o cicloturismo. }\end{array}$ \\
\hline Segovia, 2019. & $\begin{array}{c}\text { Estudo levanta questões sobre a } \\
\text { mobilidade e cicloturismo em } \\
\text { Curitiba-PR }\end{array}$ & Não. \\
\hline $\begin{array}{l}\text { Teixeira e Edra, } \\
2020 .\end{array}$ & $\begin{array}{c}\text { Artigo busca a definição do } \\
\text { termo cicloturismo. Propõe o } \\
\text { segmento turístico Viagem de } \\
\text { Bicicleta }\end{array}$ & Não. \\
\hline Viaciclo, Sem Data. & Documento que apresenta & Não. \\
\hline
\end{tabular}




\begin{tabular}{|c|c|c|}
\hline & $\begin{array}{c}\text { orientações para o poder público } \\
\text { implementar roteiros de } \\
\text { cicloturismo. }\end{array}$ & $\begin{array}{c}\text { Embora comente sobre a } \\
\text { possibilidade do } \\
\text { cicloturismo como aliado } \\
\text { na conservação ambiental. }\end{array}$ \\
\hline
\end{tabular}

Fonte: Elaborado pelos autores.

Como fica evidente, a maioria dos trabalhos sobre cicloturismo analisados não discute sobre as UC. Isto mostra a necessidade de novos estudos acadêmicos sobre a temática.

\section{CONTEXTUALIZANDO CICLISMO E SUA PRÁTICA EM UNIDADES DE CONSERVAÇÃO}

Estudos como os de Bartoletti e Magro (2016) e o de Pinto et al, (2008) pontuam que as atividades não motorizadas, como pedestrianismo e o ciclismo, são potencialmente menos impactantes negativamente do que atividades motorizadas, como o uso de veículos $4 \times 4$, motocross ou atividades a cavalo. Nota-se que o olhar para as atividades de pedestrianismo, como hikking, trecking, corridas de aventura e até mesmo atividades correlatas, como birdwatch, têm sido preponderantes nos estudos acadêmicos e esforços de manejo (BARTOLETTI e MAGRO, 2016).

Apesar disso, nota-se que os estudos sobre o ciclismo vêm tomando cada vez mais importância no mundo. Primeiramente, para questões de delimitação em relação às UC, a modalidade de bicicleta diretamente relacionada é o mountain bike (MTB) ou também conhecida como bicicleta de todo terreno (BTT). Estes tipos de bicicletas são mais robustas, adequadas para o uso em estradas e trilhas, compostas por pneus mais largos, cravejados e, normalmente, associadas às suspensões dianteira e/ou traseiras. São bicicletas associadas às práticas de mountain bike (ou ciclismo de montanha). As modalidades mais difundidas são: Cross Country (XC); Cross Country Maraton (XCM); Cross Country Olímpico (XCO); Downhill; e Enduro MTB/All Mountain (STOTT, 2019).

Entretanto, é preciso deixar claro o perfil do usuário deste tipo de bicicleta. Roldan (2000) divide o ciclismo em três grandes grupos: 1) Meio de transporte: pessoas que utilizam com grande frequência, para deslocamentos; 2) Esporte: atletas, das mais diversas modalidades, com enfoque em rendimento e performance; 3) Lazer: usuários de bicicleta, de forma não competitiva. $\mathrm{O}$ autor ainda destaca que não existe uma divisão formal deste último tipo de ciclismo, mas trabalha com mais três subdivisões: Ciclismo de longa distância: objetivo de cumprir grandes distância, no menor tempo possível, com um objetivo de superação pessoal; Cicloturismo: objetivo de fazer uma viagem, utilizando a bicicleta e necessitando de planejamento, podendo durar vários dias; Ciclismo recreativo: toda atividade de lazer, realizada informalmente e sem grande planejamento prévio (ROLDAN, 2000). 
Neste sentido, existem poucos trabalhos sobre o perfil dos usuários de bicicleta em áreas protegidas, como por exemplo, o estudo australiano de Pickering e Rossi (2016). Na verdade, no que diz respeito ao Brasil, carecem dados sobre o uso de bicicleta como um todo. O levantamento mais amplo e recente sobre o uso de bicicletas no Brasil, segundo Andrade e Rodrigues (2018), apresenta dados significativos sobre esse meio de transporte: estima-se que só no ano de 2015, foram produzidas 5 milhões de bicicletas no território nacional, com receita de quase 730 milhões de reais. $\mathrm{Na}$ dimensão científica, os pesquisadores apontam que, entre 2007 e 2017, existiram 124 projetos com o tema bicicleta, envolvendo 270 pesquisadores em 16 estados brasileiros. Apesar disso, vê-se que a maior parte destes projetos estão relacionados com a também importante área da mobilidade urbana e não diretamente com a área da conservação ambiental em UC.

O próprio levantamento de Andrade e Rodrigues (2018) apresenta um estudo de caso sobre competições de mountain bike, no qual $65 \%$ dos participantes são amadores. Sabe-se que esta modalidade de ciclismo é desenvolvida em regiões não asfaltadas, preferencialmente com mata. Mas não foram encontrados dados sobre a relação com a qual ocorrerem, mesmo que parcialmente, em UC. Entretanto, alguns dados chamam atenção: somente na competição analisada, foram registrados 4100 participantes. Além disso, no ano de 2016 aconteceram 206 competições de ciclismo em todo Brasil, o que mostra que essa é uma atividade muito praticada entre os brasileiros (ANDRADE e RODRIGUES, 2018).

Isto também se evidenciou em uma pesquisa, como a de Rosa, Teixeira e Carvalhinho (2013), que ocorreu em uma área protegida em Portugal. Nesse trabalho, mostrou-se que o MTB foi a atividade mais praticada dentro da amostra de usuários, com 68,3\%, sendo o pedestrianismo a segunda mais praticada, com 51,2\% dos usuários analisados (um mesmo usuário poderia praticar mais de uma atividade, o que explica as porcentagens apresentadas). Estes resultados levaram os pesquisadores a concluírem que é fundamental que sejam avaliados os impactos e a qualidade da experiência dos praticantes desta modalidade. Além disso, sugere que se construam locais específicos para essa prática esportiva na área protegida em questão, com uma gestão participativa dos praticantes. Trabalhos como de Rosa, Teixeira e Carvalhinho (2013), demonstram que a maioria dos praticantes de atividades físicas em áreas protegidas em Portugal os fazem por lazer, mas não apresenta o percentual por cada tipo de atividade.

Este grande uso em áreas protegidas, para prática do mountain bike, também foi encontrado no estudo de Norman, Pickering e Castley (2019). Em três parques urbanos de conservação analisados na Austrália, os pesquisadores constataram que o número de ciclistas é o dobro do número de pedestres, e estes usam uma combinação mais complexa de trilhas e exploram mais a área protegida. Este estudo também mostrou que os ciclistas utilizam majoritariamente os finais de semana, sobretudo domingos, para prática do ciclismo. Outro estudo australiano, mas valendo-se de outra metodologia, realizado por Pickering e Rossi (2016), também mostrou grande prevalência de praticantes de mountain 
bike em trilhas dos parques analisados, representando 44\% dos usuários. Os autores destacam que estes dados são compatíveis com outras pesquisas, indicando o aumento dos praticantes desta modalidade no mundo, e, consequentemente, o aumento do uso de UC.

Entretanto, dados do diagnóstico da visitação em parques nacionais e estaduais brasileiros (BRASIL, 2009) mostram que o ciclismo é a terceira atividade mais praticada, com $9 \%$ dos usuários. As duas atividades mais desenvolvidas são caminhadas de um dia $(23 \%)$ e banho $(16 \%)$. Vale lembrar que, na última década, o ciclismo tem se popularizado muito, o que deve ter ocasionado mudanças nesse perfil de usuário atualmente (ANDRADE e RODRIGUES, 2018).

Diante dos dados de aumento de uso de UC por parte de ciclistas (mountain bike) aumentam-se também as preocupações sobre o impacto ambiental destas atividades. Marion e Wimpey (2007) destacam em sua revisão bibliográfica que os estudos científicos existentes indicam que, embora o mountain bike, como todas as formas de atividade recreativa, possa resultar em impactos à vegetação, ao solo, aos recursos hídricos e à vida selvagem, os efeitos, quando bem administrados, são mínimos. Os autores pontuam que os impactos desta atividade são pouco diferentes das caminhadas, as mais comuns e tradicionais atividades recreativas em trilhas. Eles também concluem que os impactos existentes em muitas trilhas usadas por ciclistas de montanha, provavelmente, estão associados, em sua maioria, a projetos de trilhas ruins ou manutenção insuficiente, e que os gestores devem procurar primeiro corrigir as deficiências relacionadas ao projeto antes de criarem restrições para usuários de baixo impacto. Pimentel et al (2019) pontua a necessidade de se reavaliar atividades não permitidas, como o ciclismo, levando em conta o real impacto em todos os contextos. Turton (2005) aponta que uma forma importante de manejo para diminuir o impacto ambiental é a criação de trilhas exclusivas para a prática de mountain bike.

São escassas, também, as informações sobre quais UC permitem as práticas de ciclismo. Em um artigo jornalístico para o Instituto Chico Mendes de Conservação da Biodiversidade, Melo (2017) apresenta oito UC federais nas quais são permitidos o uso de bicicletas: Parque Nacional da Serra do Cipó (MG), Parque Nacional das Emas (GO), Parque Nacional dos Lençóis Maranhenses (MA), Floresta Nacional de Brasília (DF), Parque Nacional da Serra da Capivara (PI), Parque Nacional de Aparados da Serra (RS), Parque Nacional do Iguaçu (PR) e o Parque Nacional de Ubajara (CE).

\section{CONCLUSÃO}

O panorama apresentado mostra que o cicloturismo, apesar do crescimento observado, ainda está se iniciando no Brasil, carecendo de incentivo e estruturas. Sobre as recentes perspectivas de uso público de UC, sobretudo parques nacionais e estaduais, vemos que o uso de bicicleta ainda é muito restrito no país. Uma excelente associação seria o uso dos parques e o cicloturismo. Entretendo, com o levantamento bibliográfico 
realizado, nota-se escassez de possibilidades nesse sentido, com pouca oferta de locais onde a atividade possa ser desenvolvida em segurança e com estrutura bem planejada. Isso contrasta com os dados encontrados e apresentados, que mostram o cicloturismo como uma oportunidade de turismo sustentável, com potencial de valorização dos territórios urbanos, rurais e naturais.

O fato de poucos parques permitirem o uso de bicicleta é significativo para esse cenário. No que concerne aos levantamentos de pesquisas em campo, a bicicleta causa impactos negativos semelhantes ao pedestrianismo, mas os planos de manejo costumam apresentar como uma atividade de alto impacto em conjunto com outras atividades motorizadas. Isto dificulta o uso e valorização dos parques, inibindo a possibilidade de se aliar o uso sustentável por meio do cicloturismo.

Uma importante estratégia seria estimular o cicloturismo, incluindo em seus roteiros as UC, inclusive usando-as como uma das motivações para a viagem. Dados levantados por Sartori (2021) mostram que uma das principais motivações dos cicloturistas é conhecer paisagens naturais. Estes dados concordam com a pesquisa de Saldanha et al (2019), que evidenciou que as principais motivações dos cicloturistas foram a aventura e maior contato com a natureza. Desta forma, as UC poderiam ser destaques nas rotas de cicloturismo, por conciliar a aventura e o contato com a natureza. Isto seria uma forma de divulgar as áreas protegidas, criando na população o sentimento de pertencimento e destacando a importância destas áreas. Assim, seriam aliados movimentos importantes que estão crescendo nos últimos anos: o uso de bicicletas, o uso público de UC e o turismo sustentável. Esse seria um caminho com grande potencial para o cicloturismo no Brasil.

Infelizmente, ainda há um grande percurso a ser caminhado neste sentido. Como exemplo, destaca-se uma reportagem de Melo (2017), do Ministério do Meio Ambiente, que apresenta as UC nas quais são possíveis o uso de bicicleta, mas sem citar a palavra turismo. Já na matéria de Fialho (2017), do Ministério do Turismo, sobre uma rota de cicloturismo, é citada uma UC, mas brevemente, sem explorar muito o atrativo. Uma articulação dos poderes públicos, nas mais diferentes esferas, é necessária para o desenvolvimento desta atividade turística e do uso público e sustentável das UC.

No contexto apresentado, nota-se a importância do uso público das UC para auxiliar na conservação dos recursos naturais e contribuir com o desenvolvimento socioeconômico local. Dentre as formas mais comuns de uso, vem se destacando o ciclismo na modalidade mountain bike, cujos impactos ambientais negativos e positivos ainda se encontram em discussão. No contexto brasileiro, pouco se sabe sobre o uso desta modalidade nas UC, carecendo dados do perfil dos praticantes, suas concepções, bem como seus papeis na conservação ambiental.

No mesmo sentido, também fica clara a necessidade de trazer um olhar científico para o cicloturismo, com pesquisas que busquem identificar seus impactos positivos e negativos e as possibilidades de se aliar à conservação ambiental. Isto se mostra como possibilidade 
de articulação extensionista das universidades e institutos de pesquisa, trazendo grandes contribuições para a sociedade. Para isso, são necessárias a aproximação e o trabalho conjunto do poder público, pesquisadores, cicloturistas e as comunidades envolvidas.

\section{REFERÊNCIAS}

ALMEIDA, R.; RAMOS, A. P. T.; GABRIEL NETO, F. A. (2017) Circuitos de Cicloturismo como Indutores de Desenvolvimento Econômico: um estudo sobre a rota do agreste - PE. In: EDRA, F. P. M.; DECASTRO, J.; SALDANHA, L. (Org.) Cicloturismo urbano em foco. Niterói: FTH/UFF, p. 121-129. Disponível em: <http://planett.com.br/wpcontent/uploads/2019/02/AC-2016.10.pdf>. Acessado em: 30 mai. 2020.

ANDRADE, V.; RODRIGUES, J.M. (2018) Economia da Bicicleta no Brasil. Rio de Janeiro (RJ): LABMOB-UFRJ. Disponível em:

<http://www.aliancabike.org.br/downloadestudo-economia-bicicleta/00c00/ ECONOMIA_DA_BICICLETA_jul_18.pdf>. Acessado: 10 mai. 2020.

BAPTISTA, L.; COCHINSKI, V. (2015) Ciclturismo: Um olhar sobre os participantes da rota de Itapará, Irati-PR. Fórum Internacional de Turismo do Iguassu. Disponível em: <http://festivaldascataratas.com/wp-content/uploads/2015/12/5.-Cicloturismo-Um-Olharsobre-os-Participantes-da-Rota-de-Itapar\%C3\%A1-Irati-PR.pdf>. Acessado em: 30 mai. 2020.

BAPTISTA, L.; de GOVEIA, E. F. (2019) Nascimento de um produto turístico: caracterização de um atrativo rural na Terra dos Pinheirais (PR). Revista Brasileira de Ecoturismo (RBEcotur), v. 12, n. 1. Disponível em:

<https://periodicos.unifesp.br/index.php/ecoturismo/article/view/6617/4225>. Acessado em: 30 mai. 2020.

BARTOLETTI, C. T.; MAGRO, T. C. (2016) Pensando a sustentabilidade em Corridas de Aventura. Revista de Gestão de Negócios do Esporte, v. 1, p. 109-124.

BECKER, A.; BECKER, A.M.; PISONI DA SILVA, A. (2020) PEDALANDO COM TURISMO. Anais do Salão Internacional de Ensino, Pesquisa e Extensão, v. 11, n. 1, 14. Disponível em: <https://periodicos.unipampa.edu.br/index.php/SIEPE/article/view/87335>. Acessado em: 30 mai. 2020.

BELOTTO, J. C. A.; NAKAMORI, S.; PRADO, G. C. (2019) O Programa Ciclovida da UFPR e o Cicloturismo. In: SALDANHA, L.; DECASTRO, J.; BALASSIANO, R. (Org.) II Encontro para o Desenvolvimento do Cicloturismo: Circuitos de cicloturismo e Unidades de Conservação. Rio de Janeiro: COPPE - UFRJ. Disponível em: <http://planett.com.br/wp-content/uploads/2019/08/AC-2018.02-1.pdf>. Acessado em: 30 mai. 2020.

BRASIL. Sistema Nacional de Unidades de Conservação da Natureza: Lei $n .^{\circ}$ 9.985, de 18 de julho de 2000. Disponível em:

<http://www.planalto.gov.br/ccivil_03/LEIS/L9985.htm>. Acessado em: 05 mai. 2020.

BRASIL. Sistema Nacional de Unidades de Conservação da Natureza: Decreto $n^{\circ} 4.340$, de 22 de agosto de 2002. Disponível em: 
<http://www.planalto.gov.br/ccivil_03/decreto/2002/d4340.htm>. Acessado em: 05 mai. de 2020.

BRASIL. (2009) Diagnóstico da visitação em parques nacionais e estaduais. Brasília: Ministério do Meio Ambiente / Ministério do Turismo. 42 p.

CARDOSO, J. H.; KARAM, L. de M.; SANTOS, J. S. (2016) Cicloturismo e agroecologia: vetores para a sustentabilidade territorial. Embrapa Clima Temperado-Boletim de Pesquisa e Desenvolvimento (INFOTECA-E). Disponível em: <https://www.infoteca.cnptia.embrapa.br/infoteca/bitstream/doc/1075184/1/Boletim244.pdf >. Acessado em: 30 mai. 2020.

CARVALHO, T. J. L.; RAMOS, J. L.; SYDOW, E. (2013) O cicloturismo como fator de desenvolvimento da atividade turística nas cidades de Araguaína e Nova Olinda Tocantins. Revista Brasileira de Ecoturismo (RBEcotur), v. 6, n. 4. Disponível em: <https://periodicos.unifesp.br/index.php/ecoturismo/article/view/6358>. Acessado em: 30 mai. 2020.

DOS SANTOS, M. A. P. (2020) A Percepção Ambiental Como Ferramenta Estratégica De Gestão Em Unidades De Conservação. Anais do Uso Público em Unidades de Conservação, v. 8, n. 13, p. 42-50. Disponível em: <https://periodicos.uff.br/uso_publico/article/view/48258>. Acessado em: jul. 2021.

FALBO, L.; EDRA, F. P. M.; TEIXEIRA, C. (2019) Cicloturismo, potencial adormecido em Niterói. Revista de Turismo Contemporâneo, v. 7, n. 2, p. 321-340. Disponível em: <https://periodicos.ufrn.br/turismocontemporaneo/article/view/18039/12285>. Acessado em: 30 mai. 2020.

FERREIRA, S. O.; DE MELLO, G. A.; LIBERALI, R. (2010) Alterações antropométricas decorrentes de uma viagem de cicloturismo. RBPFEX-Revista Brasileira de Prescrição e Fisiologia do Exercício, v. 4, n. 22. Disponível em:

<http://www.rbpfex.com.br/index.php/rbpfex/article/viewFile/265/267>. Acessado em: 30 mai. 2020.

FIALHO, G. (2017) Novos circuitos buscam alavancar cicloturismo no Brasil. Ministério do Turismo. Disponível em: <http://antigo.turismo.gov.br/\%C3\%BAltimasnot\%C3\%ADcias/7443-novos-circuitos-buscam-alavancar-cicloturismo-no-brasil4.html\#: :text=Se\%20cada\%20vez $\% 20$ tem $\% 20$ crescido,cicloturismo $\% 20 \mathrm{t} \% \mathrm{C} 3 \% \mathrm{AAm} \% 2$ 0surgido\%20no\%20pa\%C3\%ADs>. Acessado em: 30 mai. 2020.

IHA, M. S. (2017) Os Potenciais Do Cicloturismo Urbano Brasileiro: Estudo Da Cidade De São Paulo. CICLOTURISMO URBANO EM FOCO, p. 103. Disponível em: <http://planett.com.br/wp-content/uploads/2019/02/AC-2016.08.pdf>. Acessado em: 30 mai. 2020.

JENOVEVA-NETO, R.; PINTO VIEIRA, A. C. (2019) Turismo de experiência para a região delimitada pela indicação de procedência dos Vales da uva Goethe, Sul de Santa Catarina-Brasil. Revista Turydes: Turismo y Desarrollo, v. 12, n. 26. Disponível em: <https://www.eumed.net/rev/turydes/26/vales-uvagoethe.zip>. Acessado em: 30 mai. 2020. JUNIOR, L. G.; CARMO, C. S.; COLLOCA, E. A.; CORRÊA, D.A. (2011) Projeto de educação ambiental e lazer (PEDAL): dialogando a partir do cicloturismo na 
escola. LICERE-Revista do Programa de Pós-graduação Interdisciplinar em Estudos do Lazer, v. 14, n. 4. Disponível em:

<https://periodicos.ufmg.br/index.php/licere/article/view/752/553>. Acessado em: mai. 2020.

MAGRO, T. C. (1999) Impactos do Uso Público em uma Trilha no Planalto do Parque Nacional do Itatiaia. Tese (doutorado). Escola de Engenharia de São Carlos. Universidade de São Paulo.

MARION, J. L.; COLE, D. N. (1996) Spatial and temporal variation in soil and vegetation impactson campsites. Ecological Applications. v. 6, n. 2, p. 520-530.

MARION, J. L.; WIMPEY, J. (2007) Environmental impacts of mountain biking: science review and best practices. Managing Mountain Biking, IMBA's Guide to Providing Great Riding. International Mountain Bicycling Association (IMBA) Boulder, p. 94-111.

MELO, D. (2017) 8 trilhas de bike para quem ama pedalar na natureza. Instituto Chico Mendes de Conservação da Biodiversidade. Disponível em:

<https://www.icmbio.gov.br/portal/ultimas-noticias/20-geral/9034-8-trilhas-de-bike-paraquem-ama-pedalar-na-natureza>. Acessado em: 22 junho 2020

NAZARETH, F. (2017) Pedalentos e o cicloturismo inclusivo como estímulo para pessoas que não têm hábito de viajar de bicicleta. In: EDRA, F. P. M.; DECASTRO, J.;

SALDANHA, L. (Org.) Cicloturismo urbano em foco. Niterói: FTH/UFF, p. 99-102.

Disponível em: <http://planett.com.br/wp-content/uploads/2019/02/AC-2016.07.pdf>.

Acesso em: 30 mai. 2020.

NORMAN, P.; PICKERING, C. M.; CASTLEY, G. (2019) What can volunteered geographic information tell us about the different ways mountain bikers, runners and walkers use urban reserves?. Landscape and Urban Planning, v. 185, p. 180-190.

OLAFSDOTTIR, G.; CLOKE, P.; SCHULZ, A.; VAN DYCK, Z.; EYSTEINSSON, T.; THORLEIFSDOTTIR, B.; VÖGELE, C. (2020) Health benefits of walking in nature: A randomized controlled study under conditions of real-life stress. Environment and Behavior, v. 52, n. 3, p. 248-274.

PICKERING, C. M.; ROSSI, S. (2016) Mountain biking in peri-urban parks: Social factors influencing perceptions of conflicts in three popular National Parks in Australia. Journal of outdoor recreation and tourism, v. 15, p. 71-81.

PIMENTEL, D. de S.; ANDRADE, F. S. A.; TALORA, D. C.; MAGRO, T. C. (2016) Mídia, uso público e unidades de conservação: problemas no paraíso. Anais do Uso Público em Unidades de Conservação, v. 4, p. 1-14.

PIMENTEL, D. de S.; MAGRO, T. C.; SILVA-FILHO, D. F. da. (2011) Imagens da conservação: Em busca do apoio público para a gestão de unidades de conservação. Teoria e Sociedade. n. 19. p. 144-169.

PIMENTEL, D. de S., VIDAL, M.D.; SIMONETTI, S.R.; RODRIGUES, C. G. de O.; KINKER, S.M.S.; SIMON, A.V.S.; BOTELHO, E. S. (2019) Desafios e avanços para a estruturação de uma comunidade de prática de visitação em áreas protegidas. Anais do Uso Público em Unidades de Conservação, v. 7, n. 11, p. 63-78. Disponível em:

<https://periodicos.uff.br/uso_publico/article/view/34789>. Acessado em: jul. 2021. 
PINTO, L. G.; OLIVEIRA, F.F.; ALMEIDA-ANDRADE, M.; PEDROSA, H.F.; SANTANA, W.A.; FIGUEIREDO, M.A. (2018) Atividade erosiva em trilhas de unidades de conservação: Estudo de caso no Parque Nacional da Serra do Cipó, Minas Gerais, Brasil. e-Scientia, v. 1, n. 1 .

REIS, A. F.; QUEIROZ, O. T. M. M. (2016) Turismo no Parque Estadual da Cantareira: patrimônio cultural e ambiental do Estado de São Paulo. In: A natureza e o patrimônio na produção do lugar turístico. Ituiutaba: Barlavento.

ROLDAN, T. R. R. (2000) Cicloturismo: planejamento e treinamento. Monografia (Graduação) - Faculdade de Educação Física, UNICAMP, Campinas.

ROSA, P. F.; TEIXEIRA, A; M do C. de S.; CARVALHINHO; L. A. D. (2013) Gestão Do Desporto De Natureza Em Áreas Protegidas: Estudo De Caso No Pnsac. Revista Intercontinental de Gestão Desportiva, v. 3, n. 1.

SALDANHA, L.; de SOUZA, H. A. S.; de CASTRO, J.; BALASSIANO, R. (2019) O cicloturista brasileiro 2018: uma análise socioeconômica de diferentes perfis de viajantes por bicicleta no brasil. 33 Congresso de Pesquisa e Ensino em Transportes da ANPET. Balneário Camboriú - SC. Disponível em:

<http://www.anpet.org.br/anais/documentos/2019/Modelos\%20e\%20T\%C3\%A9cnicas\%20 de\%20Planejamento\%20de\%20Transportes/Modelos\%20de\%20Demanda\%20por\%20Tran sportes\%20II/6_688_AC.pdf>. Acessado em: 30 mai. 2020.

SARTORI, A. (2020) O evento ciclístico "Pedala Trento" e suas contribuições para o cicloturismo em Nova Trento/SC e região. Revista acadêmica observatório de inovação do turismo, v. 14, n. 3, p. 1-23. Disponível em:

<http://publicacoes.unigranrio.edu.br/index.php/raoit/article/view/5631>. Acessado em jul. 2021.

SARTORI, A. (2021) Perfil do ciclista e cicloturista em Santa Catarina (Brasil): aspectos socioeconômicos e suas motivações para o uso da bicicleta. Revista Turismo em Análise, v. 32, n. 1, p. 40-58. Disponível em:

<https://www.revistas.usp.br/rta/article/view/177111/176768>. Acessado em: jul. 2021.

SEGOVIA, Y. N. S. (2019) Gestão urbana e arranjos institucionais para a política de ciclomobilidade: perspectivas de avanço no cicloturismo urbano na cidade de Curitiba, Brasil. Seminario Internacional de Investigación en Urbanismo. "XI Seminario Internacional de Investigación en Urbanismo, Barcelona-Santiago de Chile". Disponível em: 〈https://upcommons.upc.edu/handle/2117/171587>. Acessado em: 30 mai. 2020.

STOTT, T. (2019) Mountain Biking. In: Outdoor Recreation. Palgrave Macmillan, Cham, p. $163-185$.

TAHARA, A. K.; CARNICELLI FILHO, S.; SCHWARTZ, G. M. (2006) Meio ambiente e atividades de aventura: significados de participação. Motriz. Journal of Physical Education. UNESP, p. 59-64.

TEIXEIRA, C. A.; EDRA, F. P. M. (2020) Cicloturismo: Origem e conceito da palavra a partir de Koselleck. Turismo: Visão e Ação, v. 22, p. 318-333. 
TURTON, S. M. (2005) Managing environmental impacts of recreation and tourism in rainforests of the wet tropics of Queensland World Heritage Area. Geographical Research, v. 43, n. 2, p. 140-151.

VALLEJO, L. R. (2013) Uso público em áreas protegidas: atores, impactos, diretrizes de planejamento e gestão. Anais do Uso Público em Unidades de Conservação, v. 1, n. 1, p. 13-26.

VIACICLO. ASSOCIAÇÃO DOS CICLOUSUÁRIOS DE FLORIANÓPOLIS. Circuitos de cicloturismo: manual de incentivo e orientação para os municípios brasileiros.

Disponível em: <http://www.clubedecicloturismo.com.br/arquivos/Manual-CircuitosCicloturismo.pdf $>$. Acesso em: 30 mai. 2020. 